\title{
Recién egresados en pandemia.
}

\section{Recent graduates in pandemic.}

\author{
Paula Yáñez del Río ${ }^{1}$, Gonzalo Muñoz Olate ${ }^{2^{*}}$
}

1. Dentista en en Etapa de Destinación y Formación - Hospital San Pedro de Los Vilos - Jefa Servicio dental. Los Vilos, Chile. 2. Delegado Epidemiologia. Hospital San Pedro de Los Vilos, Chile.

${ }^{*}$ Correspondencia a: Gonzalo Muñoz Olate | Dirección: Arauco 400, Hospital de Los Vilos | Email: gonzalo.munoz@uchile.cl

Trabajo recibido 07/10/2021

Aprobado para su publicación 07/10/2021

\section{Estimado editor:}

Como recién egresados nos ha tocado vivir en plena revuelta social y pandemia un sin número de situaciones, que nos han puesto a desarrollar todas nuestras capacidades tanto humanas, como profesionales.

Para las localidades donde muchos profesionales en etapa de destinación y formación deben desempeñarse, no es nada ajena la situación en la cual nuestro país se encuentra, por lo cual es imperioso poder visualizar desde la primera línea odontológica, el cómo esta catarsis ha sido abordada desde nuestro sistema de salud.

Gran parte de las expectativas de un recién egresado se centran en poder ejercer en su propio terreno profesional. Según cifras de mifuturo.cl(1)en odontología a nivel nacional, sólo un $67 \%$ de los cirujanos dentistas consigue empleo al 1er año y un $84 \%$ al 2 do año. (Septiembre $2020)^{(1)}$. Esto nos deja la eterna interrogante del aumento en la oferta de cirujanos dentistas vs la baja empleabilidad, dando cuenta de la sobresaturación de egresados de odontología y nulas políticas públicas en la distribución del trabajo considerando que para la OMS se requiere 1 dentista cada 2000 habitantes, y en Chile llevamos la asombrosa cifra de 1 dentista cada 886 habitantes $^{(2,3)}$, donde en la red pública tenemos 1 dentista (44 horas) cada 5.752 personas inscritas y validadas por FONASA (dotación ley 19.378 a noviembre 2017)(4), reflejando la desigual distribución de profesionales entre la red pública y privada de atención. Además la mayoría de los odontólogos se establecen profesionalmente concentrándose en la capital del país, dejando brechas de acceso a la atención odontológica en las regiones.

Lo anterior es consecuencia directa de la aún escasa injerencia de los cirujanos dentistas en el aparato público/privado no sólo en término del accionar clínico, sino en su planificación estratégica.

Empero, la pandemia del SARS-COV-2 nos ha generado un momento único de oportunidades. Ha permitido la unificación de criterios a nivel nacional, estandarización de los protocolos de atención para mantener claras medidas de cuidado en transmisión de aerosoles, obligando al sector Público/Privado a optimizar la atención con tal de disminuir el riesgo de contagio y poder otorgar las prestaciones de salud de forma biosegura. Esta adaptación ha sido muy dinámica y cambiante, quedando en evidencia la poca preparación en epidemiología que en general se desarrolla en la malla curricular de odontología en Chile.

Esta pandemia ha revelado las carencias en salud oral de las personas con escenarios socioeconómicos más complejos, donde han aumentado las necesidades de atención, listas de espera y consultas por urgencias dentales. Por ello, hoy más que nunca frente a esta crisis mundial, debemos organizar esfuerzos e innovar en nuestra profesión, para que de alguna manera integremos nuestro quehacer profesional en el mundo del mañana, relevando la importancia de la salud oral como parte de la salud integral de las personas. Además, es menester evidenciar las necesidades de atención dental que en el día a día sigue aumentando y que de no ejercer políticas públicas masivas y eficaces con apertura de ofertas laborales descentralizadas y empoderamiento del odontólogo en los equipos multidisciplinarios, sólo se irán concentrando profesionales en los bordes de la capital confinados a su box dental.

Hoy en día nuestro sistema tiene indicios de integración de atenciones remotas, como teleconsultas espontáneas y programadas, consejerías, educación y aplicación de pautas a pacientes en control con enfoque de riesgo odontológico (CERO). La reconversión de funciones de los funcionarios con tal de hacer frente a la pandemia de Covid-19 ha dado participación a cirujanos dentistas en campañas de vacunación, direcciones de servicio y vigilancia epidemiológica. Ambos puntos han iniciado un cambio de paradigma en la visión del odontólogo por parte de la población y el resto de los agentes del equipo de salud, saliendo de la burbuja de la consulta odontológica hacia un horizonte más complejo y completo de la atención en salud.

Así el llamado final es a que los nuevos egresados se empoderen de su rol protagónico y transformador, ya que solo así, siendo agentes de cambio es como la salud oral volverá a estar en boca de todos.

\section{Bibliografía}

1. Subsecretaría de Educación Superior. Estadísticas por carrera. [Consultado 30-092021]. Disponible en: https://www.mifuturo.cl/buscador-de-estadisticas-por-carrera/ 2. Benavides C. ¿Cómo somos, cuántos somos y cuántos necesita el país? Actualización en cifras sobre dentistas y estudiantes de odontología en Chile. [Consultado 30-09-2021]. Disponible en: https://webdental.wordpress.com/2017/03/24/dentistasen-chile-como-somos-cuantos-somos-y-cuantos-necesita-el-pais/

3. Arellano-Villalón M. \& Fuentes R. Desde la admisión hasta el ejercicio profesional.
Una revisión de las carreras de odontología en Chile. Int J Odontostomat. 2020;14(4), 623-31. https://dx.doi.org/10.4067/S0718-381X2020000400623

4. Subsecretaría de Salud Pública División de Prevención y Control de Enfermedades Departamento de Salud Bucal, Ministerio de Salud. Plan Nacional de Salud Bucal 2018-2030. [Consultado 30-09-2021]. Disponible en: https://www. minsal.cl/wp-content/uploads/2017/12/Plan-Nacional-Salud-Bucal-2018-2030-Consulta-P\%C3\%BAblica-20_12_2017.pdf 